\title{
RETRACTED ARTICLE: Security monitoring for intelligent water-saving precision irrigation system using cloud services in multimedia context
}

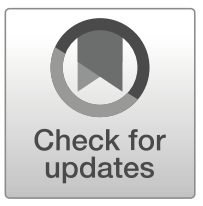

\author{
Baiqing $\operatorname{Zhou}^{1} \cdot \operatorname{Lin} \mathrm{Li}^{2}$
}

Received: 23 November 2017 / Revised: 27 November 2017 / Accepted: 29 November 2017 /

Published online: 22 December 2017

C) Springer Science+Business Media, LLC, part of Springer Nature 2017

The Editor-in-Chief has retracted this article [1], which was published as part of special issue "Multi-source Weak Data Management using Big Data", because there was evidence suggesting authorship manipulation and an attempt to subvert the peer review process.

Corresponding author Lin Li stated on behalf of both authors that they agree to this retraction.

\section{References}

1. Zhou, B. \& Li, L. Security monitoring for intelligent water-saving precision irrigation system using cloud services in multimedia context. Multimed Tools Appl (2017). https://doi.org/10.1007/s11042-017-5481-4

Electronic supplementary material The online version of this article (https://doi.org/10.1007/s11042-0175481-4) contains supplementary material, which is available to authorized users.

Lin $\mathrm{Li}$

lilin1778@126.com

1 Zhejiang Tongji Vocational College Of Science and Technology, Hangzhou Shi, Province Zhejiang, China 